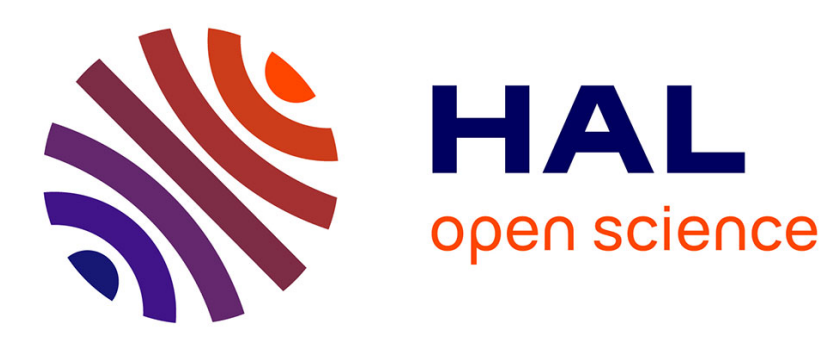

\title{
Influence of Thermal Treatment on Magnetomechanical Damping of 49Fe-49Co-2V Alloy
}

\author{
D. Shin, J. Degauque, C. Lebourg, B. Astie
}

\section{To cite this version:}

D. Shin, J. Degauque, C. Lebourg, B. Astie. Influence of Thermal Treatment on Magnetomechanical Damping of 49Fe-49Co-2V Alloy. Journal de Physique IV Proceedings, 1996, 06 (C8), pp.C8-545-C8548. 10.1051/jp4:19968119 . jpa-00254549

\section{HAL Id: jpa-00254549 https://hal.science/jpa-00254549}

Submitted on 1 Jan 1996

HAL is a multi-disciplinary open access archive for the deposit and dissemination of scientific research documents, whether they are published or not. The documents may come from teaching and research institutions in France or abroad, or from public or private research centers.
L'archive ouverte pluridisciplinaire HAL, est destinée au dépôt et à la diffusion de documents scientifiques de niveau recherche, publiés ou non, émanant des établissements d'enseignement et de recherche français ou étrangers, des laboratoires publics ou privés. 


\title{
Influence of Thermal Treatment on Magnetomechanical Damping of ${ }^{49} \mathrm{Fe}-{ }^{49} \mathrm{Co}^{2} \mathrm{~V}$ Alloy
}

\author{
D.W. Shin, J. Degauque, C. Lebourg and B. Astie
}

Laboratoire de Physique des Solides, INSA, ERS111 du CNRS, Toulouse, France

\begin{abstract}
The 2V Permendur alloy $(49 \mathrm{Fe}-49 \mathrm{Co}-2 \mathrm{~V})$ is very useful for electrical applications requiring high magnetic flux densities. The improvement of its magnetic(maximum permeability, coercive force) and magnetomechanical(damping) properties is achieved by various thermal treatments. The results are discussed according to the influence of order, grain size, internal stresses and d.c. applied field.
\end{abstract}

\section{INTRODUCTION}

Iron-cobalt alloys have been investigated for applications where high magnetic flux densities are essential. With a very high saturation magnetization $\mathrm{M}_{\mathrm{s}}$, a high Curie temperature and a low magnetocrystalline anisotropy coefficient $\mathrm{K}_{1}$, the $50 \mathrm{Fe}-50 \mathrm{Co}$ alloy, because of the cost of both the raw materials and manufacture, is generally reserved for special applications such as air borne high-speed electrical machines, compact generators, compact power transformers. Moreover, the magnetostriction constant of $50 \mathrm{Fe}-50 \mathrm{Co}$ is among the highest $\left(\lambda_{100} \approx 150.10^{-6}\right)$ of the $3 \mathrm{~d}$ element alloys; therefore Permendur sheets are able to show a strong damping of mechanical vibrations.

Unfortunately, this alloy undergoes long-range ordering, which cannot be entirely suppressed by rapid cooling no matter how severely the alloy is quenched. The ordering causes two serious problems in the attempt to convert the alloy into a useful magnetic material. One is the extreme brittleness and the other is a considerable reduction in resistivity, what increases eddy current losses. But the addition of small amounts of vanadium makes the alloy ductile enough to be hot rolled down to a thin sheet while the resistivity is only slightly increased. The result is $2 \mathrm{~V}$-Permendur $(2 \mathrm{~V}, 49 \mathrm{Fe}, 49 \mathrm{Co})$ so called to indicate the combination of good values of permeability and ductility [1]. The improvement of mechanical properties is high enough to make easy the fabrication of thin laminations of the alloy, in order to reduce the eddy current losses.

Some structural features of the material (ordering, structural defects) that depend mainly on annealing could play an essential role on its magnetic and mechanical properties. The purpose of this work is to give a better understanding of the influence of structural modifications induced by various thermal treatments on the magnetomechanical damping and the magnetic properties of the $2 \mathrm{~V}$-Permendur alloy.

\section{EXPERIMENTAL TECHNIQUES}

The composition of alloy studied is (wt. \%) : 48.62Co, $1.95 \mathrm{~V}, 0.10 \mathrm{Ni}, 0.018 \mathrm{C}$ and $\mathrm{Fe}$ balance. Samples are strips $0.25 \mathrm{~mm}$ thick, $10 \mathrm{~mm}$ wide and $80 \mathrm{~mm}$ length with a rectangular shape. The length $(80 \mathrm{~mm})$ is parallel to the rolling direction. Taking note of the ordering temperature $\left(\mathrm{T}_{\mathrm{cr}} \approx 730{ }^{\circ} \mathrm{C}\right)$, two annealing treatments are used, one at temperature around $T_{c r}$, the other over $T_{c r}$. For the higher temperature, the onset of ordering depends on the cooling rate. Heat treatments are carried out in dry hydrogen 
atmosphere for $3 \mathrm{~h}$ at $760^{\circ} \mathrm{C}$ (cooling rate $=500^{\circ} \mathrm{C} / \mathrm{h}$ : sample $\mathrm{A}$ ) and $4 \mathrm{~h}$ at $850^{\circ} \mathrm{C}$ (different cooling rates $=250,500$ and $6000^{\circ} \mathrm{C} / \mathrm{h}$ for samples $\mathrm{B}, \mathrm{C}$ and $\mathrm{D}$, respectively).

Magnetomechanical damping measurements are performed at room temperature and at $0.5 \mathrm{~Hz}$ frequency on an inverted torsion pendulum. A longitudinal magnetic field is applied by a solenoid surrounding the sample. This damping $Q_{\text {mag. }}^{-1}=\mathrm{Q}^{-1}(\mathrm{H}=0)-\mathrm{Q}^{-1}\left(\mathrm{H}_{s}\right)$ is defined as the difference between the damping in the demagnetized state and under a d.c. saturating field $\left(\mathrm{H}_{\mathrm{s}}=80 \mathrm{kA} \cdot \mathrm{m}^{-1}\right)$. It is measured almost continuously as a function of the shear strain $\gamma$ which varies between $1.8 \times 10^{-5}$ and $22 \times 10^{-5}$ at the surface of the sample. The values of $Q_{\text {mag }}^{-1}$ are corrected in order to take into account the nonuniformity of torsional deformation. Before each measurement, the samples are demagnetized. At the beginning of each set of measurements, the amplitude of the shear strain is set to a relatively high value, to induce a stable and reproducible distribution of magnetic domains.

The d.c. and a.c. magnetic properties are obtained using a single mumetal sheet tester. The coercive force $H_{c}$, relative permeability $\mu_{r}$, remanent induction $B_{r}$ and losses $W$ are determined from hysteresis loops measured at $50 \mathrm{~Hz}$ and for a maximum induction of $1.9 \mathrm{~T}$.

\section{EXPERIMENTAL RESULTS}

Figure 1 gives the magnetomechanical damping behavior $Q_{\text {mag. }}^{-1}$ as a function of shear strain $\gamma$, of samples $A, B, C$ and $D$ in the demagnetized state. Heat treatment at $850^{\circ} \mathrm{C}$ followed by a slow cooling (B and C) promotes a high damping capacity with the maximum values of $Q_{\text {mag. }}^{-1}$ obtained at lower strain amplitude, while a fast cooling (D) or an annealing at $760^{\circ} \mathrm{C}$ (A) lowers the whole damping level and the intensity of the maxima shifts to higher strain.

For sample B, figure 2 shows the effect of a longitudinal d.c. magnetic field : the value of $Q_{\text {mag. }}^{-1}$ ( $\max$ ) at first increases with the magnetic field intensity $\mathrm{H}$ and decreases after reaching a maximum value. A similar behaviour is observed for the other three samples. The large black dots are the data points; for dotted lines see below.

For the four samples, figures 3 and 4 show hysteresis loops $B(H)$ and permeability variations $\mu_{\mathrm{r}}(\mathrm{H})$, respectively. The table gives the corresponding values of $\mathrm{H}_{c}$ and maximum permeability $\mu_{r}^{\max }$. The curves of $Q_{\text {mag. }}^{-1}(\gamma)$ and magnetic parameters relative to the four samples, show obviously that the levels of maximum damping $Q_{\text {mag. }}^{-1}$ (max) of samples $\mathbf{B}$ and $\mathbf{C}$ with large $\mu_{r}^{\max }$, small $\mathrm{H}_{\mathrm{c}}$ and small $\mathrm{W}$ are high, while those of $\mathbf{A}$ and $\mathbf{D}$ samples with low $\mu_{r}^{\max }$, high $\mathrm{H}_{\mathrm{c}}$ and high $\mathrm{W}$ are relatively low.

\begin{tabular}{|c|c|c|c|c|c|c|}
\hline Sample & $\begin{array}{c}\text { Annealing in } \\
\mathrm{dry} \mathrm{H}_{2}\end{array}$ & Cooling rate & $\mathrm{Q}_{\text {mag }}^{-1}(\max )$ & $\mu_{\mathrm{r}}^{\max }$ & $\mathrm{H}_{\mathrm{o}}(\mathrm{A} / \mathrm{m})$ & $\mathrm{W}(\mathrm{W} / \mathrm{Kg})$ \\
\hline $\mathrm{A}$ & $760^{\circ} \mathrm{C}, 3 \mathrm{~h}$ & $500^{\circ} \mathrm{C} / \mathrm{h}$ & $4.17 \times 10^{-2}$ & 4040 & 130 & 5.67 \\
\hline $\mathrm{B}$ & $850^{\circ} \mathrm{C}, 4 \mathrm{~h}$ & $250^{\circ} \mathrm{C} / \mathrm{h}$ & $7.89^{\prime \prime}$ & 5120 & 97 & 4.02 \\
\hline $\mathrm{C}$ & $850^{\circ} \mathrm{C}, 4 \mathrm{~h}$ & $500^{\circ} \mathrm{C} / \mathrm{h}$ & $5.23^{\prime \prime}$ & 5510 & 110 & 4.64 \\
\hline $\mathrm{D}$ & $850^{\circ} \mathrm{C}, 4 \mathrm{~h}$ & $6000^{\circ} \mathrm{C} / \mathrm{h}$ & $2.63^{\prime \prime}$ & 4100 & 119 & 4.47 \\
\hline
\end{tabular}

\section{DISCUSSION}

Between the various structural defects which can interact with magnetic domain walls (DW's) in the studied alloy, we have first analysed the influence of the order (the interacting defects are antiphase boundaries: APB's), then that of grain boundaries and dislocations, which are effective pinning centers for DW's. Moreover, the influence of order on intrinsic properties of the material $\left(\lambda_{s}, K_{1}, M_{s}\right)$ has to be considered. 


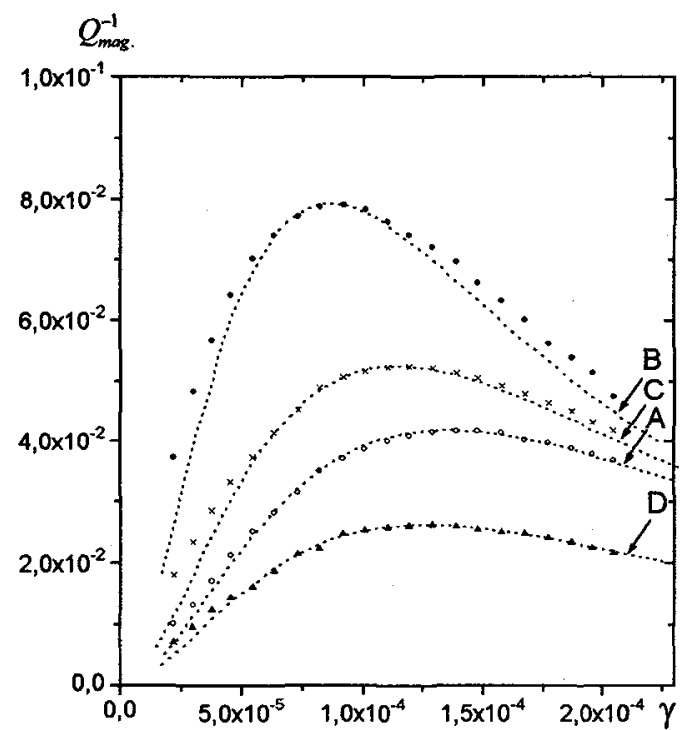

Figure 1 : Magnetomechanical damping as a function of shear strain $\gamma$ of samples.

$\mathrm{B}(\mathrm{T})$

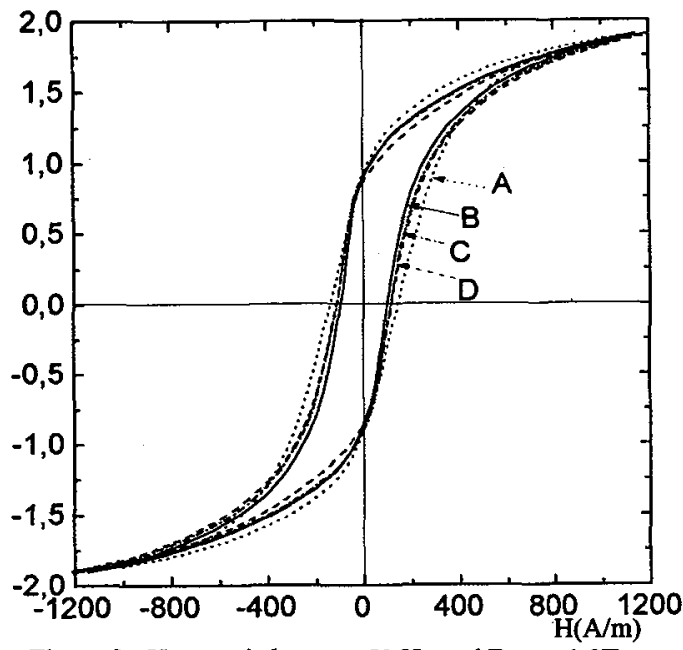

Figure 3 : Hysteresis loops at $50 \mathrm{~Hz}$ and $B_{\max }=1.9 \mathrm{~T}$

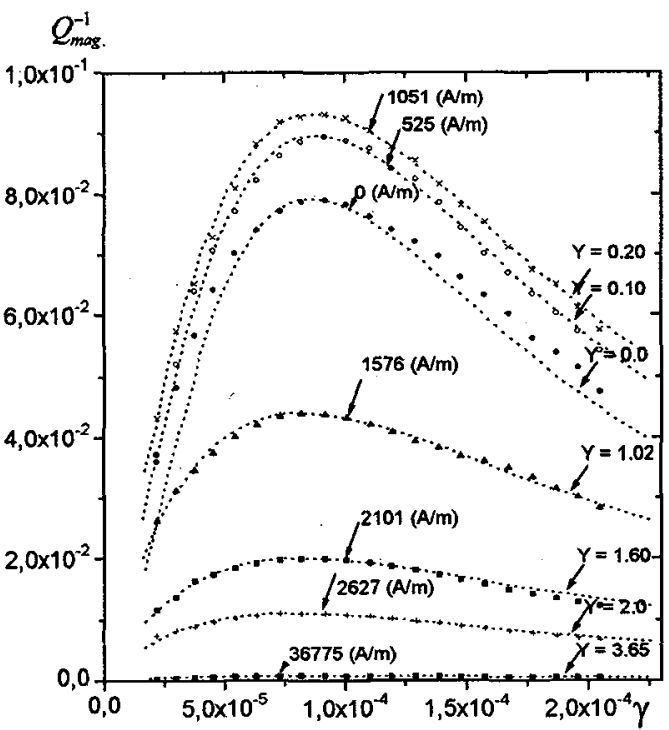

Figure $2:$ Effect of a longitudinal d.c. magnetic field for sample B ( $Y$ : see text).

$\mu_{\mathrm{r}}$

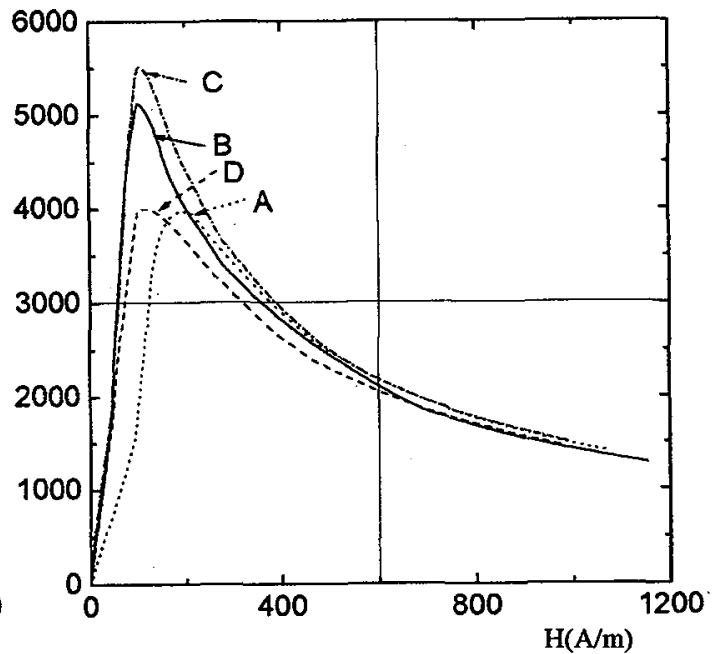

Figure 4 : Relative permeability as a function of d.c. magnetic field $(50 \mathrm{~Hz})$.

Near the composition of $50 \mathrm{Fe}-50 \mathrm{Co}$, fast ordering takes place below a critical temperature of about 730 ${ }^{\circ} \mathrm{C}$. In the disordered $\alpha$ phase, the atoms are arranged at random on the corners and at the center of a cubic unit cell. The ordered $\alpha^{\prime}$ phase has the « $\mathrm{CsCl}$ structure », in which iron atoms occupy only corner sites and cobalt atoms only the cube-center sites. This alloy has a very low magnetocrystalline anisotropy giving a soft magnetic behavior (high permeability, low coercive force) due to very easy displacements of magnetic domain walls. Ordering produces a slight increase in the saturation magnetization $M_{s}$ and in the magnetostriction $\lambda_{s}[2]$. 
First of all, for the four samples, the magnetomechanical damping is very high ( $Q_{\text {mag. }}^{-1}$ (max) is between $10^{-2}$ and $10^{-1}$ ), what can be related to the very important magnetoelastic coupling between non- $180^{\circ}$ DW's and the mechanical shear stress, due to the large value of the magnetostriction coefficient $\left(\lambda_{s} \approx\right.$ $70.10^{-6}$ ).

The samples $\mathbf{B}, \mathbf{C}$ and $\mathbf{D}$ have the same average grain size $(\approx 150 \mu \mathrm{m})$, which brings high permeability and low coercive force. The ordering is not complete and its level increases when the cooling rate is slower.

The magnetomechanical damping maximum $Q_{\text {mag. }}^{-1}(\gamma)$ is due to the irreversible displacements of non- $180^{\circ}$ DW's, induced by a vibrational stress. So, it appears that these displacements are not really influenced by the interacting defects (APB's) due to the onset of the order (from D to B) which should induce a decrease of $Q_{\text {mag. }}^{-1}$. Consequently, for the quenched alloy (D), the smaller values of $Q_{\text {mag. }}^{-1}$ (max) are likely due to the internal stresses, increased by the rapid cooling. These stresses reduce also the value of $\mu_{r}^{\max }$ and increase that of $\mathrm{H}_{\mathrm{c}}$. Sample $\mathrm{B}\left(250^{\circ} \mathrm{C} / \mathrm{h}\right)$ spread out more $\alpha$ ordered phase than sample $\mathrm{C}\left(500^{\circ} \mathrm{C} / \mathrm{h}\right)$ and thus gives higher damping since magnetostriction coefficient is increased by order. The corresponding values of $\mu_{r}^{\max }$ and $\mathrm{H}_{c}$ give evidence of the very small influence of additional internal stresses induced by the cooling rate.

The highest value of the permeability, for the cooling rate of $500^{\circ} \mathrm{C} / \mathrm{h}(\mathrm{C})$, corresponds to a low negative value of the magnetocrystalline anisotropy coefficient $\mathrm{K}_{1}[1]$. The annealing at $760^{\circ} \mathrm{C}(\mathrm{A})$ induces a grain refinement (average grain size $\approx 80 \mu \mathrm{m}$ ) which enhances the mechanical properties [3] but makes the motions of DW's more difficult : $\mathrm{H}_{\mathrm{c}}$ and $\mathrm{W}$ increase, while $\mu_{r}^{\max }$ and magnetomechanical damping decrease.

The ability of a d.c. magnetic field $\mathrm{H}$ to improve the magnetomechanical damping, when properly applied, is shown in figure 2 . The increase of the magnetomechanical damping arises from the initiating influence of $\mathrm{H}$ on irreversible jumps of magnetic domain walls induced by the vibrational stress. Quantitative analysis of the observed field dependencies is based on our model [4,5] giving the magnetomechanical damping $Q_{\text {mag. }}^{-1}$ of a ferromagnetic sample under a static magnetic field H.- $Q_{\text {mag. }}^{-1}$ is supposed to be directly proportional to the number of DW's which make reproductible magnetomechanical hysteresis loops, moving rigidly in the field of force of structural defects. This number, which depends on the values of the stress and of the magnetic field $\mathrm{H}$ ( $\mathrm{Y}$ in figure 2 is directly proportionel to $\mathrm{H}$ ), is calculated using proper distribution functions of local internal stresses ( or maxima of field of force) opposed to the motion of DW's [4].

Dotted line curves in figure 2 give the variation of the theoretical values of $Q_{\text {mag. }}^{-1}$ plotted as a function of the strain for different values of $\mathrm{Y}$ (ie $\mathbf{H}$ ). There is evidently a rather close correlation between experimental points and theoretical variation of magnetomecanical damping in presence of a d.c. magnetic field.

\section{CONCLUSION}

Various heat treatments applied to a $2 \mathrm{~V}$ Permendur alloy, show that an increase of both grain size and ordering can improve, simultaneously and very markedly, its magnetic and magnetomechanical properties.

\section{References}

[1] Couderchon G., Tiers J.F., J.M.M.M. 26 (1982) 196.

[2] Hoselitz H., Ferromagnetic Properties of Metals and Alloys (Oxford, Clarendon Press 1952).

[3] Gautard D., Couderchon G., Coutu L., J.M.M.M. to be published.

[4] Degauque J., Thesis, University of Paul Sabatier, Toulouse, 1977.

[5] Augustyniak B., J. of Alloys and Compounds, 211/212 (1994) p. 563. 